\title{
RADIAL THERMOELECTRIC GENERATOR MODULES FOR IN-LINE POWER GENERATION FROM HOT GAS STREAMS
}

\author{
Israel Boniche ${ }^{*}$ and David P. Arnold
}

Interdisciplinary Microsystems Group, University of Florida, Gainesville, FL, USA

\begin{abstract}
This paper reports the fabrication and characterization of stackable silicon-micromachined thermoelectric generator (TEG) modules for power generation from hot gas streams. Each module employs radially oriented thermoelements on a thermally insulating polyimide layer extending between inner and outer finned silicon structures. Power is generated by flowing hot gas through the center orifice, which creates a radial thermal gradient across the thermopile. Metal thermoelements are used to demonstrate the concept, resulting in $60 \mathrm{mV}$ open-circuit voltage and delivery of $0.45 \mu \mathrm{W}$ of power $\left(0.01 \mathrm{~mW} / \mathrm{cm}^{3}\right.$ power density) from a single TEG module to a $1.5 \mathrm{k} \Omega$ resistive load using a $200{ }^{\circ} \mathrm{C}$ hot gas stream. Analytic models indicate that replacing the metal thermoelements with higher-performing semiconductor alloys can increase the output power, e.g. $\sim 0.5 \mathrm{~mW}\left(10 \mathrm{~mW} / \mathrm{cm}^{3}\right)$ using $\mathrm{Bi}_{2} \mathrm{Te}_{3}$ at $200{ }^{\circ} \mathrm{C}$, or $\sim 1.3 \mathrm{~mW}\left(27 \mathrm{~mW} / \mathrm{cm}^{3}\right)$ using $\mathrm{PbTe}$ alloys at $400{ }^{\circ} \mathrm{C}$.
\end{abstract}

\section{MOTIVATION}

The need for long-lasting wireless electronic devices with increasing functionality has stimulated research of alternative power sources to traditional batteries. Additionally, there is great interest for energy harvesters that can locally generate power for wireless sensor networks from ambient environmental energy. Some popular scavenging methods include solar cells, vibrational devices, and thermoelectric generators (TEGs) $[1,2]$. If a persistent heat source is available, TEGs are attractive solid-state devices that can directly convert heat energy into electrical energy. The lack of moving parts and the ability to create electrical power from any heat source facilitates a reliable and versatile power generation mechanism.

The goal of the proposed TEG device is to convert waste thermal energy into electrical energy from hot gas exhaust streams. For instance, the device could be coupled to the hot exhaust of a microcombustor or micro heat engine to directly generate useful load power, or perhaps for supplementary power to run auxiliary components such as switches, valves, pumps, or sensors [2, 3]. Alternatively, a TEG module could be used for self-powered sensors/systems wherever hot gas or liquid lines are present, e.g. automobiles, aircraft, or industrial environments.

At PowerMEMS 2007, we demonstrated the feasibility of micromachining silicon substrates with polymer membranes as thermally insulating platforms for radially oriented in-plane thinfilm TEGs [4]. This work expands on those efforts by evaluating the overall device performance with the inclusion of functional thermoelements (the prior proof-of-concept demonstrators did not include thermoelements). The focus of this paper is the fabrication and characterization of the individual TEG modules using thin-film metal thermoelements. Stacked modules are not reported here. These results validate the concept and provide baseline experimental data for thermoelectric models. This in turn paves the way for second-generation devices using semiconductor thermoelements with substantially improved power output.

\section{DEVICE DESCRIPTION}

The overall structure consists of silicon-micromachined thermoelectric modules that can be stacked to form a cylindrical heat exchanger with finned surfaces on both the hot and cold sides As shown in Fig. 1, each module consists of two concentric silicon rings connected by a thermally insulating $5-\mu \mathrm{m}$-thick polyimide membrane that supports radially patterned thin films thermoelements. Hot gas flows through the finned central channel heating the inner surface, while outer annular fins keep the outer surfaces cool via natural or forced convection. A large, uniform temperature gradient $(\Delta T)$ is thus established across the radially oriented thermoelements ( $1 \mathrm{~mm}$ long, $0.5 \mu \mathrm{m}$ in thickness) within each module.

This design provides good thermal isolation and easy in-line insertion into hot gas streams, which overcomes a key inadequacy of the standard parallel-plate thermoelectric module for the intended application. Moreover, the ability to stack modules enables scalability, so that multiple modules can be connected for more power.

The work here presents modules using $\mathrm{Ni}$ and $\mathrm{Au}$ thermoelements. It is well known that semiconductors such as $\mathrm{Bi}_{2} \mathrm{Te}_{3}$ and $\mathrm{PbTe}$ alloys yield superior thermoelectric performance [2], but these films are more difficult to fabricate as compared to simple sputtering of metal thin-films. Also, the $\mathrm{Ni}$ and $\mathrm{Au}$ films exhibit desirable properties such as good adhesion to the polyimide layer and good solderability for electrical connections.

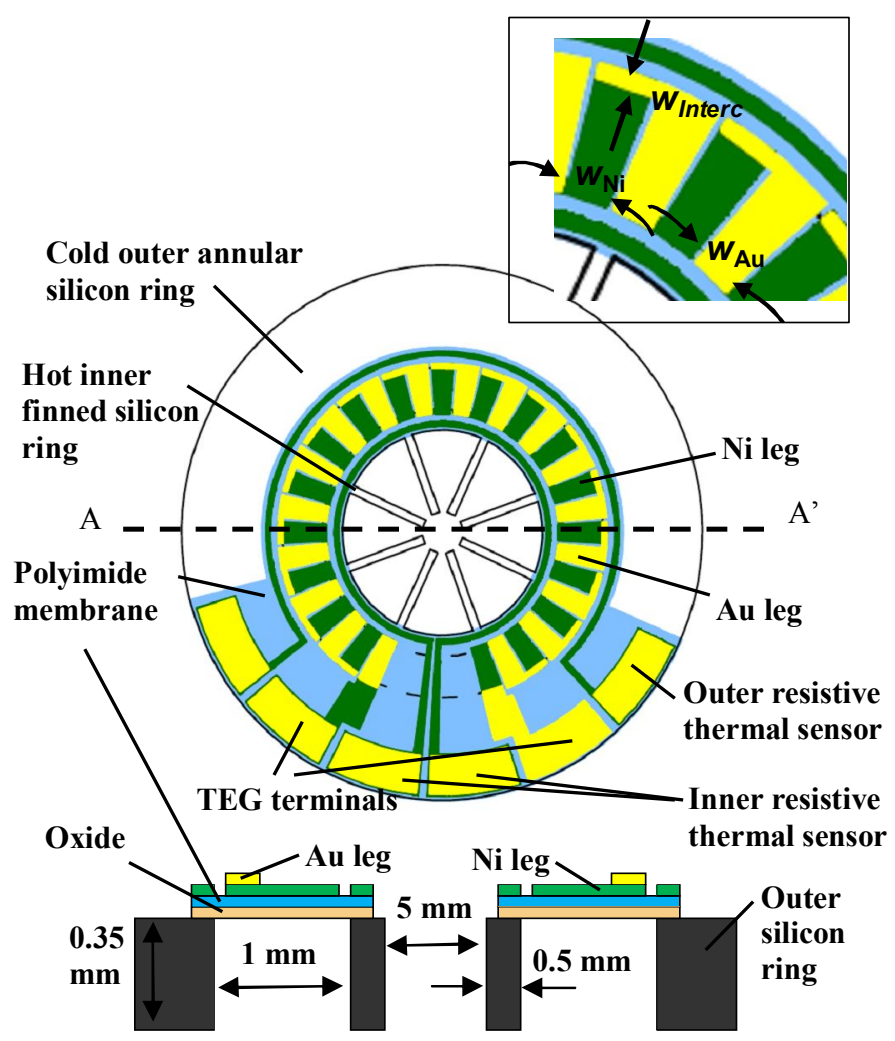

Figure 1: Top view and cross-section of thermoelectric generator module with hot center ring and cold outer silicon ring connected by a polyimide membrane. 


\section{FABRICATION}

Three different module designs with different number of $\mathrm{Ni} / \mathrm{Au}$ thermocouple pairs $(n)$ were fabricated. The geometries for the selected designs are shown in Table 1. The TEG modules also included circular Ni resistive structures for temperature sensing of the inner and outer silicon rings, as shown in Fig 1. On-wafer electrical test structures were also fabricated for characterization of the thin-film resistivities and contact resistance.

Table 1. Selected TEG designs using thin-film Ni and $A u$ thermoelements.

\begin{tabular}{|l|l|l|l|}
\hline Leg Pairs, $n$ & 18 & 65 & 90 \\
\hline Ni leg width, $w_{\mathrm{Ni}}(\mu \mathrm{m})$ & 377 & 40 & 10 \\
\hline Au leg width, $w_{\mathrm{Au}}(\mu \mathrm{m})$ & 377 & 50 & 10 \\
\hline Spacing between legs $(\mu \mathrm{m})$ & 90 & 90 & 90 \\
\hline $\begin{array}{l}\text { Inner and outer interconnect } \\
\text { width, } w_{\text {Interc }}(\mu \mathrm{m})\end{array}$ & 100 & 100 & 100 \\
\hline Ni thickness, $t_{N i}(\mu \mathrm{m})$ & 0.5 & 0.5 & 0.5 \\
\hline $\mathrm{Au}$ thickness, $t_{A u}(\mu \mathrm{m})$ & 0.5 & 0.5 & 0.5 \\
\hline
\end{tabular}
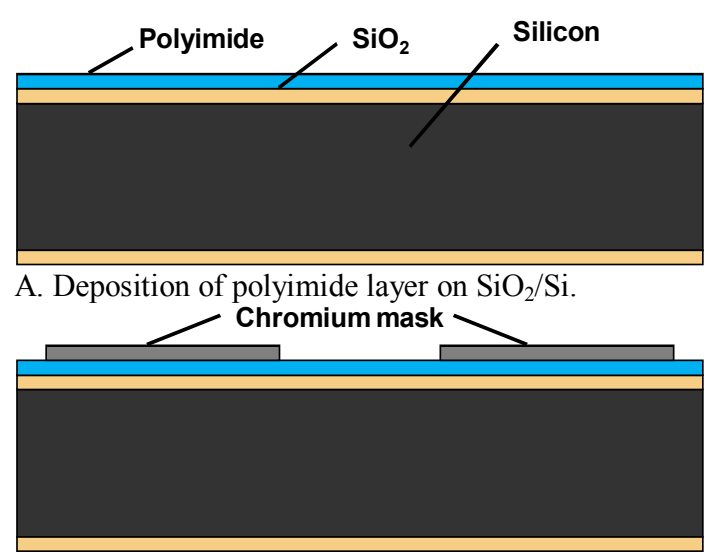

B. Deposition and patterning of chromium mask. Patterning of Polyimide and $\mathrm{SiO}_{2}$

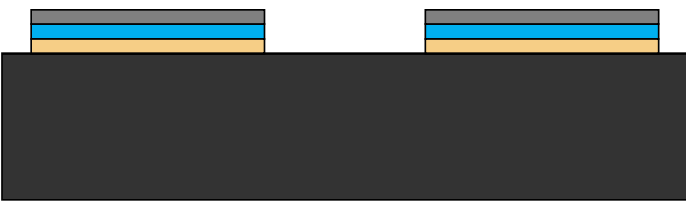

C. Patterning annular polymide/ $/ \mathrm{SiO}_{2}$ rings with $\mathrm{Cr}$ mask.

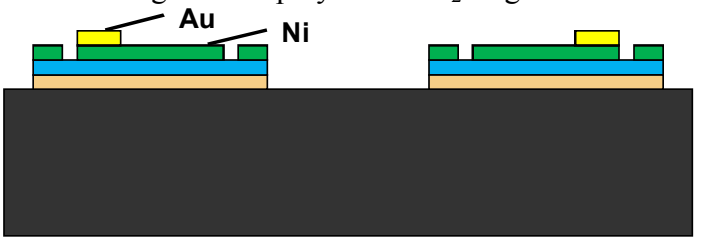

D. Deposition and patterning of thin film Ni and Au TE metals.

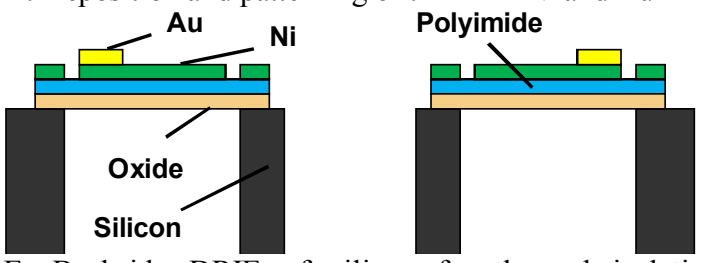

E. Backside DRIE of silicon for thermal isolation, channel formation and device release.

Figure 2: Fabrication process of a radial TE generator module.
The fabrication process starts with a $\sim 345$ - $\mu$ m-thick, doubleside polished, and thermally oxidized silicon wafer. First, a nonphotodefinable polyimide film (PI 2611 from Microsystems Inc.) is spin-deposited on the top surface (Fig. 2a). Then, by using a thin-film chromium mask (Fig. $2 \mathrm{~b})$, annular polyimide $(\sim 5 \mu \mathrm{m})$ and oxide rings are patterned with an $\mathrm{O}_{2}$ plasma etch and bufferedoxide etch, respectively (Fig. 2c). Next, dc-sputter deposition and lift-off is used to form the $\mathrm{Ni}(\sim 0.5 \mu \mathrm{m})$ thermoelement legs and the Ni resistive sensors. This is followed by sputtering and lift-off of $\mathrm{Au}(\sim 0.5 \mu \mathrm{m})$ (Fig. $2 \mathrm{~d})$.

After completing the topside processing, the wafer is mounted face down with photoresist to a handle wafer for backside processing. A deep reactive ion etch (DRIE) is performed to form the fin arrays and hot gas channel (Fig. 2e). Simultaneously, silicon is selectively etched away from underneath the thermopile, stopping on the oxide. After completion, the individual chip modules, shown in Fig. 3, are carefully removed from the handle wafer by immersion in acetone and rinsing with methanol and deionized water.

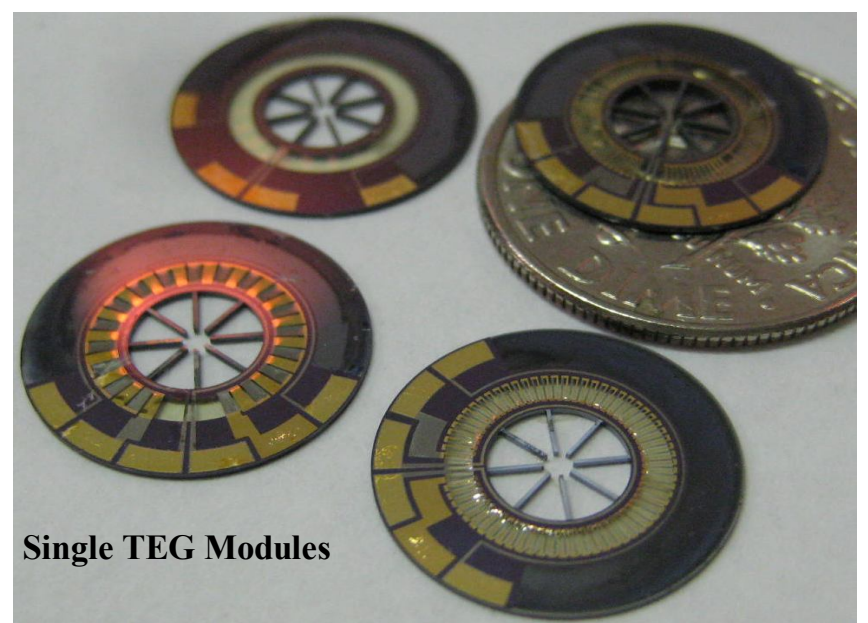

Figure 3: TEG modules fabricated on silicon substrates using thinfilm Ni-Au thermoelements. Resistive thin film Ni also included for temperature sensing of the inner and outer silicon rings. Inner and outer diameters are $5 \mathrm{~mm}$ and $13 \mathrm{~mm}$, respectively.

\section{RESULTS}

Using the on-wafer test structures (van der Pauw and transfer length method), the thin-film metal electrical resistivities $(\rho)$ were characterized [5]. The Au thin film exhibited a resistivity $(2.6 \pm 0.7$ $\mu \Omega$-cm) similar to the bulk value $(2.3 \mu \Omega-\mathrm{cm})$, while the $\mathrm{Ni}$ showed a high resistivity of up to $108.2 \pm 7.8 \mu \Omega-\mathrm{cm},>10 \mathrm{X}$ than the bulk value [6]. While the variance from bulk was not entirely unexpected, the results for the sputtered Ni films here also differed from other reported $\mathrm{Ni}$ thin films [7]. The large resistivity differences may be attributed to differences in film thickness, deposition conditions, substrate, and film defects. From the electrical resistivity measurements, the thermal conductivities $(\kappa)$ of the thin metal films were estimated by using the WiedemannFranz law [2]. The $\mathrm{Au}$ thin film was estimated with a thermal conductivity of $285.2 \pm 73.4 \mathrm{~W} / \mathrm{m} \cdot \mathrm{K}$, while the $\mathrm{Ni}$ was estimated with a relatively low thermal conductivity of $6.8 \pm 0.5 \mathrm{~W} / \mathrm{m} \cdot \mathrm{K}$. From the transfer length method test structures, the Au-Ni specific contact resistivity $\left(\rho_{c}\right)$ was estimated at $\sim 15 \pm 15 \mu \Omega-\mathrm{cm}^{2}$.

For the module characterization, thin copper wires were soldered to the gold bond pads for external electrical connections. First, the thermal resistive sensors integrated on the TEG were 
characterized by measuring the temperature-resistance behavior to determine the linear temperature coefficient of resistance (TCR), $\alpha_{\mathrm{TCR}}$. Each TEG module was placed inside an oven (Lindberg Blue $\mathrm{M})$ with the resistive sensor wire leads leading out to Keithley 2400 source meters for 2-pt resistance measurement. The temperature sensors were calibrated from ambient temperature up to $\sim 200{ }^{\circ} \mathrm{C}$. The extracted TCR values for various Ni rings were fairly consistent with each other, with the mean of the 8 different rings estimated at $2.67 \times 10^{-3}{ }^{\circ} \mathrm{C}^{-1}$, and the lower and upper $(95 \%)$ confidence intervals ranging from $2.55 \times 10^{-3}{ }^{\circ} \mathrm{C}^{-1}$ to $2.79 \times 10^{-3}{ }^{\circ} \mathrm{C}^{-1}$.

Next, the module thermopile resistances were measured and compared against calculated values. The estimated resistances were determined from thin-film properties, and for all cases, the total contact resistance (despite the large uncertainty) was negligible $(<0.1 \%$ of the total resistance) and thus ignored. A breakdown of the resistance is shown in Table 2 for the three different modules. For the $n=65$ design, the legs and interconnects contributed $95 \%$ and $5 \%$, respectively, of the total resistance. Interconnects contributed only $1 \%$ for the $n=90$ design (having the largest resistance at $11.3 \mathrm{k} \Omega$ ), but $39 \%$ for the $n=18$ design.

Table 2. Two-point dc current measurements and model estimates of electrical resistance at $25^{\circ} \mathrm{C}$ for TEGs using Au-Ni leg pairs. In parenthesis are the percentages of the total TEG resistance attributed to the legs and interconnects [8].

\begin{tabular}{|l|l|l|l|}
\hline Leg Pairs $(n)$ & 18 & 65 & 90 \\
\hline Measured total resistance, & $0.123 \pm$ & $1.63 \pm$ & $11.3 \pm$ \\
$\mathrm{R}_{\text {Total }}(\mathrm{k} \Omega)$ & 0.003 & 0.003 & 0.003 \\
\hline Estimated total resistance, & $0.108 \pm$ & $2.24 \pm$ & $12.4 \pm$ \\
$\mathrm{R}_{\text {Total }}(\mathrm{k} \Omega)$ & 0.036 & 0.74 & 4.1 \\
\hline Estimated legs resistance, & 0.065 & 2.13 & 12.3 \\
$\mathrm{R}_{\text {Legs }}(\mathrm{k} \Omega)$ & $(61 \%)$ & $(95 \%)$ & $(99 \%)$ \\
\hline Estimated interconnect & 0.042 & 0.101 & 0.137 \\
resistance, $\mathrm{R}_{\text {Interc }}(\mathrm{k} \Omega)$ & $(39 \%)$ & $(5 \%)$ & $(1 \%)$ \\
\hline
\end{tabular}

For thermoelectric characterization, individual TEG modules were evaluated using a heat gun as the source of a hot gas stream as shown in Fig. 4. Output voltage measurements were made using a high-precision digital voltage meter (SIM 970 module from SRS). A segment of a high-temperature-resistant tubing (0.25-inch diameter) and a custom-made aluminum fixture were coupled to the heat gun outlet to channel the hot gas to the $5 \mathrm{~mm}$ inner diameter of the TEG module. The module was positioned within 2 $\mathrm{mm}$ of the fixture, and aligned to the hot gas stream. The upstream and downstream hot gas temperatures were simultaneously measured using two bare-wire type $\mathrm{K}$ thermocouples. The inner and outer $\mathrm{Ni}$ resistances were measured with two source meters and temperatures extracted using the TCR values.

The open-circuit voltage $\left(V_{o c}\right)$ as a function of the downstream gas temperature $\left(T_{G A S}\right)$ is shown in Fig. 5. For a given gas temperature, the design with largest number of legs $(n=90)$ exhibited the largest generated voltage (e.g. $45 \mathrm{mV}$ at $\sim 120{ }^{\circ} \mathrm{C}$ ). However, at a test temperature of $\sim 200^{\circ} \mathrm{C}$, the design with $n=65$ leg pairs generated up to $60 \mathrm{mV}$. Fig. 6 shows $V_{o c}$ as a function of $\Delta T=T_{\text {Hot }}-T_{\text {Cold }}$, which should follow the relationship given by [2]

$$
V_{O C}=n \cdot\left(\alpha_{A u}-\alpha_{N i}\right) \cdot \Delta T=n \cdot\left(\alpha_{A u-N i}\right) \cdot \Delta T
$$

For each module, the Seebeck coefficient, $\alpha_{A u-N i}$ is thus given by the slope of the least-square fit line divided by $n$. The extracted Seebeck values were close to one another with $95 \%$ certainty bounds of $14.3 \pm 0.9 \mu \mathrm{V} / \mathrm{K}$. The values here were higher than the Seebeck coefficient $(\sim 10 \mu \mathrm{V} / \mathrm{K})$ reported for evaporated thin-film $\mathrm{Au} / \mathrm{Ni}\left(0.2 / 0.1 \mu \mathrm{m}\right.$ in thickness) thermoelements on $\mathrm{SiO}_{2} / \mathrm{Si}$ [9].

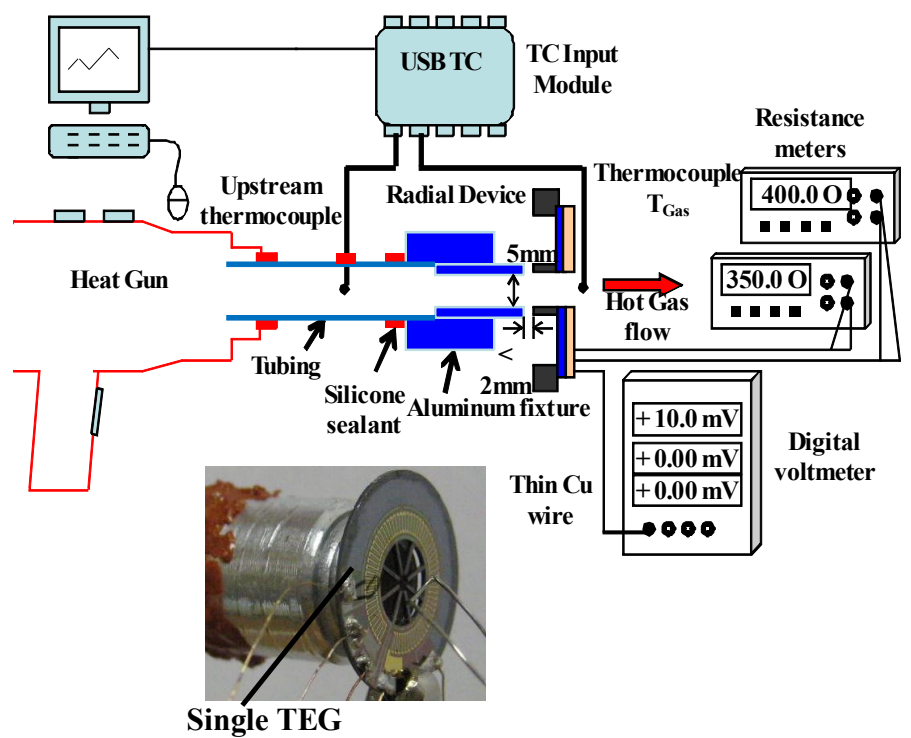

Figure 4: Setup for thermal and electrical characterization of single radial TEGs using a heat gun as source for a hot gas stream.

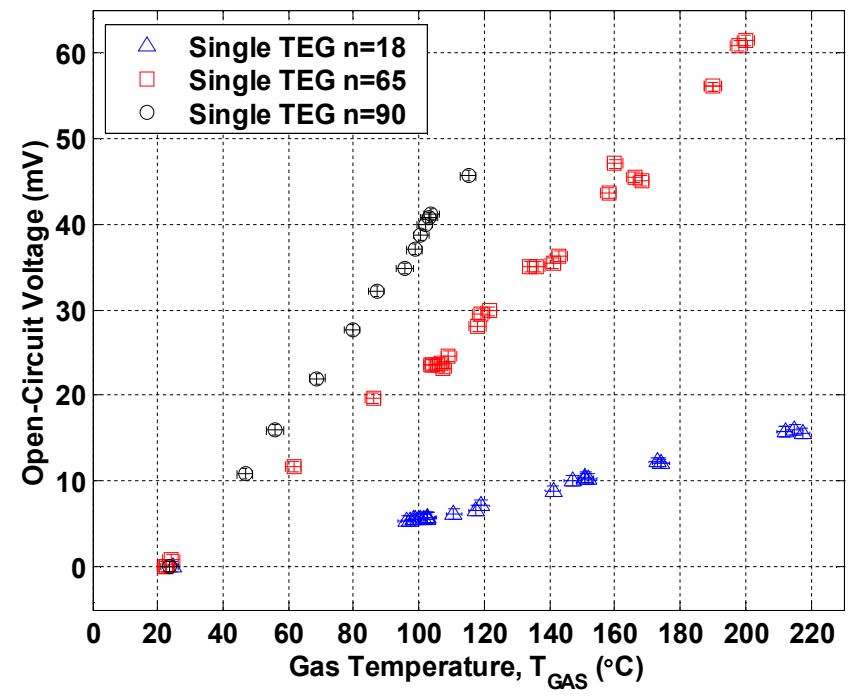

Figure 5: Open-circuit voltage as a function of gas temperature for various TEG modules having small uncertainties in the voltage $( \pm 0.6 \mathrm{mV})$ and $T_{G A S}\left( \pm 2.5^{\circ} \mathrm{C}\right)$.

In addition to the open-circuit voltages, the TEG modules were tested with resistive loads, and the power output was measured for the different TEG designs. Initially, "matched" resistive loads were used where the load resistance roughly equals the module resistance, for maximum power transfer. Specifically, load resistances of $0.120 \mathrm{k} \Omega, 1.55 \mathrm{k} \Omega$, and $11.5 \mathrm{k} \Omega$ were used to approximate the resistance for the $n=18,65$, and 90 designs, respectively. The power output was calculated by measuring the voltage across the resistive load according to the equation

$$
P_{L}=\frac{V_{L}^{2}}{R_{L}}
$$

where $V_{L}$ is the load voltage, and $R_{L}$ is the load resistance. 


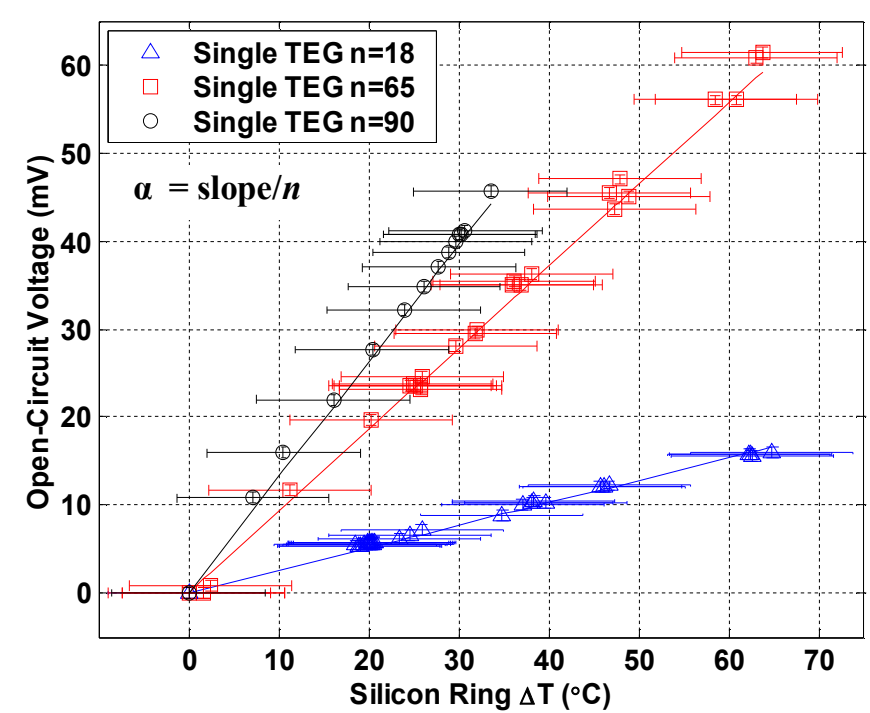

Figure 6: Open-circuit voltage as a function of silicon ring temperature difference for various TEG modules.

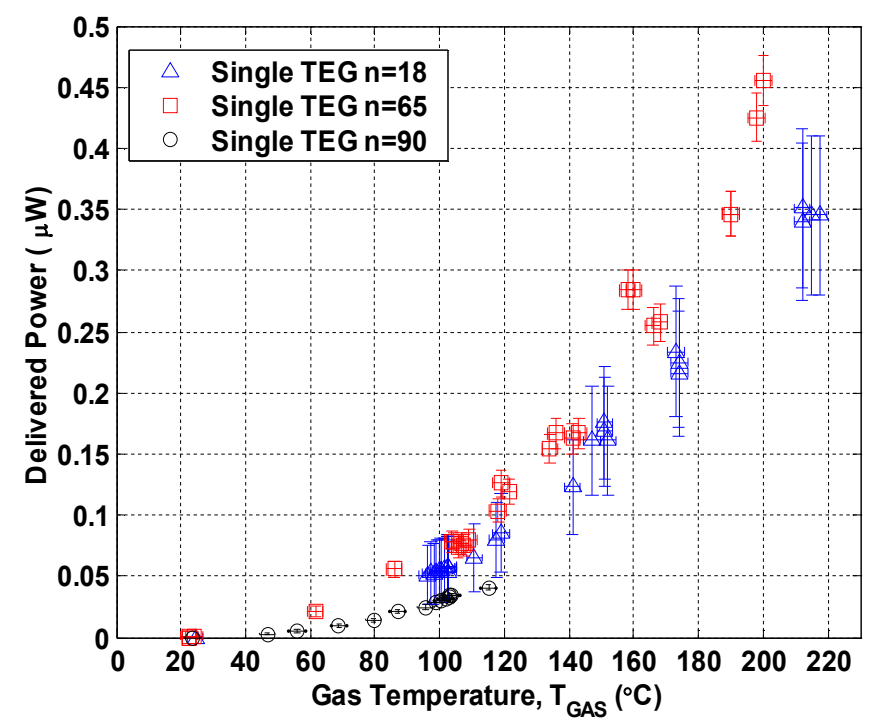

Figure 7: Power output for single TEG modules as a function of gas temperature by using resistive loads 'matching' the TEG device resistance.

As shown in Fig. 7, the output power increased quadratically with gas temperature, as expected from Eq. 2 (since the voltage increased linearly with gas temperature). The intermediate design $(n=65)$ showed higher output power compared to the other two designs ( $n=18$ and $n=90)$. Overall, at a gas temperature of $200{ }^{\circ} \mathrm{C}$, a maximum power output of $\sim 0.45 \mu \mathrm{W}$ was measured for the $n=65$ design by using a $1.55 \mathrm{k} \Omega$ load, which approximated the TEG module resistance of $\sim 1.63 \mathrm{k} \Omega$.

Fig. 8 shows the power output for the $n=65$ design for various loads and temperatures. An unexpected cooling of the outer silicon ring (at a gas temp. of $171^{\circ} \mathrm{C}$ ) resulted in a larger than expected $\Delta T$ resulting in an increase in load voltage and power. Ignoring the anomalous behavior at $171{ }^{\circ} \mathrm{C}$, a maximum power of $0.36 \mu \mathrm{W}$ was measured for $191{ }^{\circ} \mathrm{C}$ gas flow using a $2 \mathrm{k} \Omega$ load which was slightly higher than the room-temperature TEG module resistance $(\sim 1.63 \mathrm{k} \Omega)$.

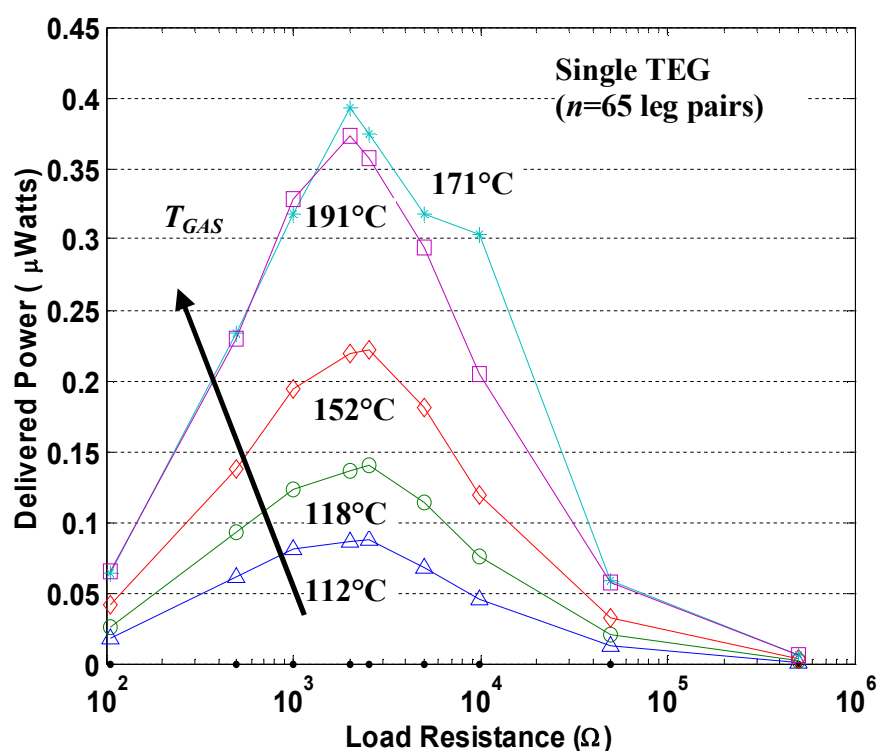

Figure 8: Power output for various resistive loads over different gas temperatures for a single TEG module $(n=65)$.

\section{CONCLUSIONS}

Coin-sized, radial thermoelectric modules using thin-film Au$\mathrm{Ni}$ thermoelements were micromachined on silicon substrates and characterized using hot gas streams. For an inlet gas temperature of $200{ }^{\circ} \mathrm{C}$, a single TEG module ( $n=65 \mathrm{leg}$ pairs) sustained a $\Delta T$ of $\sim 65{ }^{\circ} \mathrm{C}$. Moreover, the thermocouple pair Seebeck coefficient $\left(\alpha_{A u-}\right.$ ${ }_{N i}$ ) was determined to be $\sim 14 \mu \mathrm{V} / \mathrm{K}$, in line with expectations for the thin-film metals used. Additionally, the TEG module with $n=65$ leg pairs $(\sim 1.6 \mathrm{k} \Omega)$, generated open-circuit voltages, $V_{O C}$, of up to $60 \mathrm{mV}$ per module, corresponding to a delivered power of $0.45 \mu \mathrm{W}$, for a gas temperature of $200{ }^{\circ} \mathrm{C}$. Analytic models [8] indicate that replacing the metal thermoelements with higherperforming semiconductor alloys can increase the output power, e.g. $\sim 0.5 \mathrm{~mW}\left(10 \mathrm{~mW} / \mathrm{cm}^{3}\right)$ using $\mathrm{Bi}_{2} \mathrm{Te}_{3}$ at $200{ }^{\circ} \mathrm{C}$, or $\sim 1.3 \mathrm{~mW}$ $\left(27 \mathrm{~mW} / \mathrm{cm}^{3}\right)$ using PbTe alloys at $400{ }^{\circ} \mathrm{C}$. Future work includes investigating semiconductor TE films on the radial TEG module as well as developing interconnect methods for stacking of multiple modules for higher power output.

\section{REFERENCES}

[1] J.P. Thomas, et al. J. Power Sources, Vol. 159, (2006), p. 1494-1509.

[2] D.M. Rowe (editor), Thermoelectrics Handbook: Macro to Nano, Boca Raton, FL (2006).

[3] A.H. Epstein, J. Eng. for Gas Turbines and Power, Trans. of the ASME, Vol. 126, (2004), p. 205-226.

[4] S. Masilamani, et al. PowerMEMS 2007, Germany, (2007), p. 249-252.

[5] D.K. Schroder, Semi. Mat. and Device Charact., $2^{\text {nd }}$ Ed., N.Y: Wiley, (1998).

[6] D.R. Lide (editor), CRC Handbook Chem. and Phys., Boca Raton, FL, London: CRC (2008).

[7] M.A. Angadi, et al., Thin Solid Films, Vol. 79, (1981), p.149153.

[8] I. Boniche, Elect. Comp. Eng., Doctorate, Gainesville, FL, Univ. of FL, (2010).

[9] D. Chu, et al., Transd. 2003, $12^{\text {th }}$ Int. Conf. Solid-State, Sens., Act., and Microsyst., Boston, Mass. (2003), p. 1112-1115.

\section{CONTACT}

*Israel Boniche, tel: +1-505-794-8593; iboniche@gmail.com 